\title{
A arte do teatro Clown no cuidado às crianças hospitalizadas
}

THE ART OF CLOWN THEATER IN CARE FOR HOSPITALIZED CHILDREN

EL ARTE DEL TEATRO CLOWN EN EL CUIDADO DE NIÑOS HOSPITALIZADOS

\section{Regina Aparecida Garcia de Lima ${ }^{1}$, Eliete Farias Azevedo ${ }^{2}$, Lucila Castanheira Nascimento ${ }^{3}$, Semiramis Melani Melo Rocha ${ }^{4}$}

\section{RESUMO}

A hospitalização pode ser uma experiência traumática para as crianças e seus familiares. $\mathrm{O}$ objetivo deste estudo foi explorar a experiência da utilização da arte do teatro clown no cuidado as crianças hospitalizadas, a partir de uma atividade desenvolvida por alunos de cursos de graduação da área da saúde. Os dados foram obtidos mediante observação de 20 crianças e 11 alunos, personagens do teatro clown em interação na clínica pediátrica de um hospital-escola do interior do estado de São Paulo. Os dados empíricos foram analisados segundo a análise temática de conteúdo, os quais foram agrupados ao redor dos seguintes temas: expressões artísticas como forma de comunicação, participação do binômio criança e acompanhante e o clown como recurso terapêutico. Os resultados indicaram que esta experiência constituiu-se em uma intervenção concreta que valoriza o processo de desenvolvimento infantil, pois abre espaço para a fantasia, o riso, a alegria e a apropriação do cotidiano hospitalar; é um exemplo de ampliação do processo diagnóstico e terapêutico com a incorporação de intervenções que privilegiem as necessidades afetivas, emocionais e culturais da criança e sua família, na busca do cuidado atraumático.

\section{DESCRITORES}

Criança hospitalizada.

Jogos e brinquedos.

Enfermagem pediátrica.

\begin{abstract}
Hospitalization can be a very traumatic experience for children and their family members. The purpose of this study was to explore the experience of using clown theater art in the care for hospitalized children, starting with an activity developed by undergraduate students in the healthcare area. Data were obtained by observing 20 children and 11 students, characters in the clown theater interacting in the pediatric clinic in a school hospital in the state of São Paulo. The empirical data were analyzed with the thematic content analysis, which were grouped around the following themes: artistic expressions as a form of communication, participation of the binomial child and accompanying partner, and the clown as a therapeutic resource. The results show that this experience was a concrete intervention, emphasizing the children's development process, since it opens up a space for fantasy, laughter, happiness and the appropriation of the hospital routine; it is an example of widening the diagnostic and therapeutic process with the incorporation of intervention focusing on the affective, emotional and cultural necessities of the child and the family, in the search for non-traumatic care.
\end{abstract}

\section{KEY WORDS}

Child, hospitalized.

Play and playthings.

Pediatric nursing.

\section{RESUMEN}

La hospitalización puede ser una experiencia traumática para los niños y sus familiares. El objetivo de este estudio fue explorar la experiencia de la utilización del arte del teatro clown en el cuidado de niños hospitalizados, a partir de una actividad desarrollada por alumnos de cursos de graduación del área de la salud. Los datos fueron obtenidos mediante la observación de 20 niños y 11 alumnos, personajes del teatro clown en interacción en la clínica pediátrica de un hospital escuela del interior del estado de San Pablo. Los datos empíricos fueron analizados según el análisis temático del contenido, los cuales fueron agrupados alrededor de los siguientes temas: expresiones artísticas como forma de comunicación, participación del binomio niño y acompañante y el clown como recurso terapéutico. Los resultados indicaron que esta experiencia se constituyó en una intervención concreta que valoriza el proceso de desarrollo infantil, ya que abre espacio para la fantasía, la risa, la alegría y la apropiación de lo cotidiano en el hospital; además es un ejemplo de ampliación del proceso diagnóstico y terapéutico con la incorporación de intervenciones que privilegian las necesidades afectivas, emocionales y culturales del niño y su familia, en la busca del cuidado sin traumas.

\section{DESCRIPTORES}

Niño hospitalizado.

Juego e implementos de juego.

Enfermería pediátrica.

\footnotetext{
${ }^{1}$ Enfermeira. Professora Associada do Departamento de Enfermagem Materno-Infantil e Saúde Pública da Escola de Enfermagem de Ribeirão Preto da Universidade de São Paulo. Ribeirão Preto, SP, Brasil. limare@eerp.usp.br ${ }^{2}$ Graduanda. Escola de Enfermagem de Ribeirão Preto da Universidade de São Paulo/Centro Colaborador para o Desenvolvimento da Pesquisa em Enfermagem da Organização Mundial da Saúde. Ribeirão Preto, SP, Brasil. elieteazevedo@yahoo.com.br ${ }^{3}$ Enfermeira. Professora Doutora do Departamento de Enfermagem Materno-Infantil e Saúde Pública da Escola de Enfermagem de Ribeirão Preto da Universidade de São Paulo/Centro Colaborador para o Desenvolvimento da Pesquisa em Enfermagem da Organização Mundial da Saúde. Ribeirão Preto, SP, Brasil. lucila@eerp.usp.br ${ }^{4}$ Enfermeira. Professora Titular do Departamento de Enfermagem Materno-Infantil e Saúde Pública da Escola de Enfermagem de Ribeirão Preto da Universidade de São Paulo. Ribeirão Preto, SP, Brasil. smmrochaa@eerp.usp.br
} 


\section{INTRODUÇÃO AO TEMA}

Atualmente, a assistência à criança hospitalizada tem dado importância significativa às terapias complementares, ao processo diagnóstico e terapêutico convencionais, no intuito de privilegiar, também, as necessidades afetivas, emocionais, sociais e culturais da criança, na busca do cuidado atraumático, definido como a provisão de cuidados terapêuticos com intervenções que eliminem ou minimizem o desconforto psicológico e físico experimentado pelas crianças e seus familiares ${ }^{(1)}$.

Para minimizar os agravos decorrentes da hospitalização, algumas estratégias podem ser implementadas, como a presença constante de um familiar junto à criança; informações precisas sobre a sua doença e o tratamento; respeito às etapas evolutivas e aos marcos do desenvolvimento infantil; oferecimento de um ambiente mais aconchegante no qual a criança sinta-se motivada e estimulada a brincar de forma mais ativa ${ }^{(2-3)}$.

Na vida da criança, o brincar é fundamental para que o seu crescimento e desenvolvimento sejam harmônicos. Quando transferida para o contexto da hospitalização, onde a rotina de vida modifica-se e altera-se pela doença, o brincar surge como uma possibilidade de organização dessas atividades, uma via fundamental para a compreensão do momento pelo qual está passando. $\mathrm{O}$ ato de brincar poderá favorecer a criança aproveitar os recursos disponíveis no contexto da hospitalização para elaborar a nova situação(4).

O valor terapêutico do brinquedo fica evidente porque auxilia a criança no processo de adaptação à hospitalização, uma vez que possibilita liberar temores, raivas, frustrações e ansiedade; facilita a comunicação entre ela e a equipe cuidadora; estimula seu desenvolvimento físico, psicológico, social e moral; aperfeiçoa as habilidades psicomotoras, e ainda favorece seu equilíbrio físico com a finalidade de preservar e restaurar sua integridade orgânica ${ }^{(1,4-6)}$.

Brincar é uma atividade séria, ao contrário do que muitos pensam não significa apenas passar o tempo. $\mathrm{O}$ ato de brincar deve constituir-se de atividades estimulantes, divertidas, criativas e enriquecedoras. No hospital, brincar torna o ambiente menos traumatizante e mais alegre, o que contribui para a recuperação da criança ${ }^{(6)}$, proporcionando-Ihe momentos de higiene mental, espaço para expressão de sentimentos oriundos da doença e da internação e a manutenção de uma relação estável entre a criança, sua família( ${ }^{(7-9)}$ e a equipe de saúde.

Na organização das unidades pediátricas, segundo padrões da medicina flexneriana, considera-se científico o que pode ser mensurável, objetivo e controlado por meio de experimentos e relega-se, por que não dizer, refuta-se as emoções e a subjetividade. Com os avanços da tecnologia, os profissionais de saúde de posse de todo aparato médi- co-hospitalar encontram-se preparados para o tratamento da doença; nesse processo cabe ao paciente aplicar, aceitar e concordar com o tratamento. Outros autores ${ }^{(1,4,6)}$, com os quais concordamos, advogam a necessidade de se mudar o enfoque, ou seja, centrar o olhar na criança e no adolescente enfermo e não na doença e, nessa perspectiva, a arte, a recreação, o lazer e o brinquedo também ganham importância. Instituições de saúde por todo o mundo já reconhecem o valor social e terapêutico da arte aplicada à medicina, e a tendência de incluí-la entre as atividades hospitalares é crescente. Diversas formas de expressões artísticas têm sido desenvolvidas no hospital, desde as clássicas, como teatro, pintura, desenho, mímica, literatura, até o teatro clown, uma das mais novas.

\section{O Clown no processo terapêutico}

Em 1986, Michael Christensen, diretor do Big Apple Circus, de Nova lorque, foi convidado a participar das comemorações do Dia do Coração no Columbia Presbyterian Babies Hospital, quando optou por fazer uma satirização às rotinas médicas e hospitalares, utilizando o teatro Clown. $\mathrm{O}$ resultado surpreendeu a todos, pois as crianças que se encontravam deprimidas e apáticas participaram ativamente das atividades propostas. Após outras visitas, o hospital decidiu investir na continuidade do trabalho, nascendo então a Clown Care Unit ${ }^{(7)}$

Em 1988, Wellington Nogueira, ator brasileiro que na ocasião morava em Nova lorque, passou a integrar a troupe do Clown Care Unit, e ao retornar ao Brasil, em 1991, criou um programa-irmão do Clown Care Unit do Big Apple Circus, iniciando as atividades no Hospital e Maternidade Nossa Senhora de Lourdes, em São Paulo. O projeto brasileiro, batizado com o nome de Doutores da Alegria, tinha como objetivo utilizar a arte do teatro clown para avaliar a necessidade das crianças hospitalizadas e colocar ao seu dispor truques, magia e malabarismo. Com isso, devolveria à criança um pouco do controle, sobre o corpo e sobre sua vida, que lhe é totalmente tirado quando se encontra enferma e hospitalizada e ainda favoreceria uma atitude mais positiva e ativa em relação à enfermidade e sua recuperação. O humor é um recurso essencial para auxiliar na superação dos traumas inerentes aos processos de enfermidade e internação, e também na restituição da alegria, parte integrante da vida da criança ${ }^{(8)}$.

Os resultados do projeto Doutores da Alegria foram analisados em dissertação de mestrado ${ }^{(7)}$ e a visível mudança de comportamento das crianças foi apontada como o resultado mais marcante: crianças que antes estavam prostradas mostraram-se mais ativas; as quietas passaram a se comunicar melhor e a se queixar menos de dores e ainda passaram a se alimentar e aceitar melhor a medicação, os exames e a própria internação. No geral, a imagem da hospitalização tornou-se menos hostil, com reflexos diretos na aceleração da recuperação e da cura. Para a equi- 
pe, o estresse da rotina diminuiu, e isso facilitou o trabalho e melhorou a integração entre os profissionais.

Em 1995, um grupo de alunos da disciplina Enfermagem Pediátrica ministrada no $7^{\circ}$ semestre do Curso de Graduação em Enfermagem da Escola de Enfermagem de Ribeirão Preto da Universidade de São Paulo manifestou interesse em desenvolver um trabalho com crianças e adolescentes hospitalizados, com base na proposta dos Doutores da Alegria.

Inicialmente, desenvolveu-se uma oficina de trabalho intitulada Assistência à criança: humanização hospitalar através da arte, com o objetivo de permitir que os participantes (alunos de graduação e pós-graduação, enfermeiras pediátricas e docentes da disciplina Enfermagem Pediátrica e Neonatal) vivenciassem a experiência da humani zação hospitalar a partir de relatos de experiências complementados por dinâmicas com exercícios de sensibilização. Esta oficina foi ministrada pelo próprio coordenador do grupo Doutores da Alegria, juntamente com outros atores integrantes da trupe ${ }^{(6)}$.

Somando a esta experiência os conhecimentos das disciplinas Psicologia e Enfermagem Pediátrica, criou-se a COMPANHIA DO RISO - Cia do Riso, com o objetivo de resgatar o riso da criança e do adolescente hospitalizados, dos seus familiares e da equipe de saúde, mediante atividades, como: cantigas de roda, mágicas, improvisações, danças, dramatizações, jogos infantis e músicas, apoiados em técnicas do teatro clown. Cada clown tem sua própria identidade e estilo, ou seja, carrega suas marcas registradas: nariz vermeIho, instrumental característico do ambiente hospitalar (estetoscópios coloridos, maletas espalhafatosas), violões, pandeiros e assobios. Assim, duas vezes por semana, a Cia do Riso, com seus personagens clowns, passou a habitar as enfermarias infanto-juvenis de um hospital-escola do interior do Estado de São Paulo.

\section{OBJETIVO}

O objetivo deste estudo foi explorar a experiência da utilização da arte do teatro clown no cuidado as crianças hospitalizadas, a partir de uma atividade desenvolvida por alunos de cursos de graduação da área da saúde (Enfermagem, Medicina, Informática Médica e Farmácia e Bioquímica).

\section{MÉTODO}

Optamos pela abordagem qualitativa, cujo fundamento é o conhecimento sobre os indivíduos a partir da descrição da experiência humana, tal como ela é vivida por seus próprios autores ${ }^{(10)}$. Para tanto, a pesquisa não pode ocorrer em espaço construído artificialmente pelo pesquisador. Ela exige observações de situações cotidianas em tempo real(11).

Em observância à legislação que regulamenta a pesquisa que envolve seres humanos, encaminhamos o protocolo de pesquisa ao Comitê de Ética em Pesquisa da institui- ção onde o trabalho de campo foi realizado, tendo o mesmo recebido aprovação (Processo n. 6995/2001).

Participaram do estudo 20 crianças internadas na Clínica Pediátrica de um hospital-escola do interior do estado de São Paulo, mais os 11 participantes da Cia do Riso, composta por alunos de cursos da área da saúde (Enfermagem, Medicina, Informática Médica e Farmácia e Bioquímica). A técnica nuclear para a interlocução com os sujeitos pesquisados foi a observação participante ${ }^{(10)}$, que possibilitou descrever e situar os fatos únicos e os cotidianos para se construírem as cadeias de significados. Esta técnica também permitiu acompanhar e registrar os movimentos, as ações e os discursos ${ }^{(12)}$ de crianças, familiares, alunos e equipe de saúde e ainda as relações que se estabeleceram naquele espaço e tempo focalizados.

Para atender o objetivo proposto, estabelecemos algumas diretrizes para a observação, ou seja, a unidade de observação ficou direcionada à interação entre crianças internadas na Clínica Pediátrica e os participantes da Cia do Riso. $\mathrm{Na}$ ocasião observamos o tipo de atividade desenvolvida; o grau de participação da criança e como ocorreu a interação: se houve necessidade de estímulo da mãe ou participação de outras pessoas. Cada observação durou, em média, 20 minutos.

A coleta de dados foi realizada durante o segundo semestre de 2005, em dois dias da semana, por uma aluna de iniciação científica treinada para este procedimento. Inicialmente, procedeu-se à apresentação dos objetivos do estudo as mães ou acompanhantes das crianças e, diante da concordância e anuência da própria criança na participação da pesquisa, solicitou-se a assinatura do termo de consentimento livre e esclarecido. O mesmo procedimento foi realizado para obtenção do consentimento dos alunos integrantes da pesquisa.

Semanalmente, procedemos à supervisão do processo de coleta de dados, buscando rigor na sistematização da coleta. A etapa operacional ocorreu, inicialmente, com o registro das observações organizado em duas partes: uma descritiva e outra reflexiva. Na primeira, registrou-se detalhadamente o que ocorreu no campo, ou seja, a descrição dos participantes, a reconstrução dos diálogos, a descrição dos locais, eventos e as atitudes dos participantes. A parte reflexiva das anotações incluiu comentários do observador relativos a sentimentos e dúvidas. Nas situações impossíveis de registros simultâneos estes foram feitos o mais próximo do momento da observação, dada a possibilidade de falhas de memórias em casos de longa espera para o registro. Os passos da observação foram: 1) observação descritiva, cuja função é fornecer ao pesquisador um orientação, para desenvolver questões de pesquisa e linhas de visão mais concretas; 2) observação focal, na qual a perspectiva restringe progressivamente aqueles processos essenciais à questão da pesquisa; 3) observação seletiva, ocorre no fim da coleta de dados e concentra-se em encontrar mais evidências para os tipos de práticas descobertos na segunda etapa(12).
A arte do teatro Clown no cuidado

às crianças hospitalizadas

Lima RAG, Azevedo EF, Nascimento LC, Rocha SMM 
Para garantir o anonimato das crianças, substituímos seus nomes por letras, na seqüência alfabética. Para os participantes da Cia do Riso, mantivemos o nome fantasia; ainda como forma de identificação, adotamos a sigla O (de observação), seguida de um número que significou o dia em que a observação foi realizada.

O material empírico foi digitado e organizado em arquivos individuais, tendo a análise percorrido as etapas preconizadas pela técnica de análise temática de conteúdo, ou seja, pré-análise, análise dos sentidos expressos e latentes, elaboração das temáticas e análise final(12). Agrupamos os dados ao redor de três temas: expressões artísticas como forma de comunicação, participação do binômio criança e acompanhante e o clown como recurso terapêutico.

\section{RESULTADOS}

\section{Expressões artísticas como forma de comunicação}

Neste item apresentamos as expressões artísticas utilizadas na interação entre os membros da Cia do Riso e as crianças participantes do estudo: música, dramatização, literatura infantil e mágica.

A música, principal expressão usada, geralmente era acompanhada por instrumentos musicais (violão, flauta e pandeiro), gestos e representações, e em quase todas as visitas, ela dava início à interação, pois através dela a Cia do Riso anunciava: estamos chegando!! Como exemplo, a situação descrita a seguir:

A criança observa as palhacinhas ${ }^{(a)}$ cantarem Quem está batendo na portinha. Depois se esconde, mas logo em seguida reaparece com um largo sorriso $(\mathrm{O} .8, \mathrm{H})$.

As palhacinhas estão na porta da enfermaria cantando Quem está batendo na portinha. A criança observa as palhacinhas entrarem com ar sorridente $(\mathrm{O} .10, \mathrm{~J})$.

Observamos que a música é um estímulo para a criança se movimentar, já que muitas canções incluem gestos e movimentos corporais:

[...] a mãe, sorridente, diz: ela gosta daquela [música] dos Polegares e canta com o grupo. Criança começa a sorrir e a movimentar os dedos $(\mathrm{O} .11, \mathrm{~A})$.

A criança olha atentamente os movimentos das mãos da palhacinha e balança os braços, enquanto canta a música A Dona Aranha $(0.3, \mathrm{C})$.

Quando a criança apresenta alguma limitação física que a impede de participar da atividade, o grupo se empenha em incluí-la, mas respeita suas limitações, como descrito a seguir:

É a música da Casinha [ela sugere movimentos de corpos agachando e se levantando]; assim a criança também faz os gestos sempre observando e imitando os movimentos

(a) As alunas integrantes da Cia do Riso são conhecidas pelas crianças por Palhacinhas e assim serão identificadas daqui por diante nas falas extraídas dos relatórios de observação empírica. das palhacinhas e das outras crianças. Na hora de abaixar, ela o faz, mas no momento de pular, senta-se e mesmo a mãe dizendo para voltar para a atividade, ela diz que não [...] [está com dreno de tórax] $(\mathrm{O} .12, \mathrm{M})$.

Algumas músicas são de autoria dos próprios alunos, compostas com finalidades específicas, ou seja, estimular a criança a adotar mudanças de hábitos, incentivá-la na alimentação ou para satirizar alguns procedimentos e rotinas hospitalares.

Uma outra estratégia adotada foi a leitura de estórias infantis, fruto muitas vezes, da imaginação dos próprios alunos, improvisadas de acordo com cada momento específico. Elas eram contadas para distrair ou atrair a atenção da criança:

A Pipoca diz que vai contar a história das formiguinhas (começa a correr os dedos na perna da criança, fazendo cócegas) A criança dá risada [...] $(\mathrm{O} .16, \mathrm{Q})$

A criança chora por estar sem a companhia da mãe que necessitou se ausentar por algum tempo para resolver problemas particulares [esta foi a justificativa da criança]. A aluna se aproxima da criança e pergunta por que ela chora e recebe como resposta que quer a mãe junto dela, mas que precisou sair e está demorando para voltar. A aluna pergunta o que pode fazer para ajudar a criança a esperar pela mãe e recebe como resposta me conte uma história. Fraidei sentase ao lado da criança e começa a contar uma história sobre uma mãe que precisava trabalhar para ganhar dinheiro e sustentar sua família. Ao final criança diz que a mãe da história ficava mais tempo longe dos filhos do que a sua mãe $(0.12, B)$.

Esta experiência possibilitou à aluna estabelecer uma forma de comunicação diferenciada com a criança, já que em muitas situações a argumentação lógica e racional pode não ser a melhor fonte de informação.

A mágica também foi outro recurso utilizado com intuito de estimular a interação e participação da criança nas brincadeiras. Normalmente, as crianças a partir de 4 ou 5 anos de idade participam melhor deste tipo de atividade, dado ao seu estágio de desenvolvimento, conforme observação a seguir:

Jubinha diz: vou fazer uma mágica! E a criança diz que também sabe fazer mágica. Jubinha começa fechando os olhos, balança a cabeça e movimenta os dedos sobre as cartas de baralho [todos se concentram]. Pede, então, que a criança assopre as cartas [novamente se concentram]. A criança dá gargalhadas, quando vê as bolinhas [que estão na carta] mudarem de cor [...] Depois, a criança tenta repetir a mágica com a mãe $(\mathrm{O} .15, \mathrm{P})$.

A Pipoca e a Jubinha fazem a mágica das cores e a criança dá risada e ajuda na concentração assoprando a carta e balançando os dedos [...] A Pimentinha ajuda dando as dicas, a criança observa e segue todas as regras. Depois que a Pipoca tira a carta, tenta confundir a criança dizendo que a carta que ela tirou não é a mesma escolhida anteriormente. A criança pede que repita mais duas vezes o truque e na última vez como não consegue adivinhar, quer saber como fazer para acertar $(0.14,0)$. 


\section{Participação do binômio criança e acompanhante}

Neste tema, abordamos o nível de participação da criança e do acompanhante nas atividades desenvolvidas pela Cia do Riso, e também pudemos constatar que a presença do acompanhante no ambiente hospitalar facilitava a comunicação da criança com os alunos da Cia do Riso; na maioria das vezes, a mãe era a acompanhante. Em algumas situações era o próprio acompanhante que levava a criança até os alunos da Cia do Riso, ajudando-a a interagir e participar ativamente das brincadeiras. Para as mães, a atividade recreacional é uma estratégia que distrai os fiIhos e minimiza o estresse presente nos processos de hospitalização(4), como exemplo:

Mãe e filha aparecem na porta da enfermaria, ambas sorrindo ao som da música Xópim Bom [parodiando o hospital]. As palhacinhas perguntam onde todos estão, ao final da música e a mãe responde sorrindo: no Xópim e pergunta para a filha se é isso mesmo ou não $(0.1, A)$.

As palhacinhas entram e perguntam do que querem brincar e como as crianças não se manifestam, uma mãe responde que quer cantar e chama as crianças da enfermaria para participarem. Quando começam a cantar Alecrim [cantiga de roda] a mãe fala para a filha bater palma em acompanhamento da música e então todas as crianças da enfermaria batem palmas no ritmo da música $(O .7, G)$.

Quando a criança estabelecia um contato prévio com a Cia do Riso, tanto sua participação quanto do seu acompanhante eram maiores, conforme observação abaixo:

\begin{abstract}
A mãe comenta que seu filho é um pouco tímido e por isso fica sério durante as brincadeiras, mas que adora as visitas da Cia, inclusive já tinha pedido a ela para colocar a camisa do Corinthians para que as palhacinhas vissem [...] $(\mathrm{O} .5, \mathrm{E})$.

A mãe diz que o filho gosta muito das palhacinhas e que perguntou se hoje elas viriam. Responde que sim e pergunta se ele lembra de alguma palhacinha. A criança balança a cabeça afirmativamente e diz que lembra de uma com um chapeuzão grande, meio amarelo, que toca viola $(\mathrm{O} .15, \mathrm{P})$.
\end{abstract}

O indivíduo que vivencia uma doença grave necessita estar em contato com algo oposto à doençca(7,13-14) e esta pode ser uma das justificativas para a presença da Cia do Riso no ambiente hospitalar, como observado nos trechos abaixo:

A mãe comenta: que bom que vieram cantar para ele, as musiquinhas deixam ele mais calmo! Voltando depois à enfermaria ouvi outras mães falando que as músicas acalmavam até elas (O. 2, B).

A mãe comenta que o melhor momento do hospital é quando as palhacinhas chegam, pois antes delas chegarem está sempre um clima de tristeza; ao chegarem o clima muda, mas quando vão embora tudo fica triste novamente $(0.12, M)$.
Algumas crianças vêm ao encontro das palhacinhas tão logo percebem o barulho da trupe. Para exemplificar:

Ao ouvir uma das palhacinhas dizer que já vamos lá, a criança diz: já tô indo também! e entra correndo no quarto (O.15 P)

\section{O clown como recurso terapêutico}

Como recurso terapêutico, o clown abre canais diferenciados de comunicação, constituindo-se em uma via de acesso que permite à criança exteriorizar seus medos, dores, angústias e limitações.

A participação da criança nas atividades da Cia do Riso (brincadeiras, jogos e dramatização) pode mudar o foco da rotina da hospitalização. No relato que se segue, podemos observar a inversão de papéis, momento em que a criança encontra o seu clown numa brincadeira de médico e paciente, quando ela assume o papel de dominador e as palhacinhas, o de dominadas. Durante a interação, a criança demonstra ter conhecimento de sua doença, das medicações que usa, das rotinas hospitalares e até de situações estressantes, como, notificar o diagnóstico de uma doença grave, um tumor, por exemplo. Uma outra característica presente nesta observação é que a criança torna-se o centro das atenções, todos ficam submissos a ela, às suas ordens, às suas conclusões e vontades, como no relato a seguir:

As palhacinhas entram na enfermaria e a criança está em pé ao lado da mãe com um estetoscópio de plástico, cor de rosa, no pescoço. Ela diz: hoje eu sou a dotôra! A Fraidei insiste que está com dor de barriga e a criança diz: deixa eu examinar! Coloca o estetoscópio na barriga da Fraidei e exclama: Santo Deus, eu vou ter que pedir uns exames! Fraidei, com voz aflita, diz: se tiver que tirar a roupa eu não faço! A criança em tom firme diz: você quer ou não quer ficar curada? Os exames são só pra quinta-feira! A paciente concorda e então a dotôra chama a próxima paciente. Flaflu, apontando para o joelho, diz: dói aqui! E a criança diz: vou examinar o seu joelho, onde que é? Flaflu diz: não sei! A criança, muito determinada: seu problema não tem cura, é hereditário! [criança tem Fibrose Cística, doença de caráter hereditário]. Todos riem! Criança chama: a próxima! Xeléia senta-se na cadeira enquanto a dotôra pergunta o nome dela e se aproxima. Xeléia diz que está doendo e se encolhe impedindo de ser examinada. A dotôra insiste e coloca o estetoscópio na barriga da Xeléia. Criança diz: pronto! Você tem uma coisa rara, todo mundo tem. Você não consegue ir no banheiro! Xeléia, aos prantos: que que eu faço? Criança diz: vai no banheiro! Todos riem. Criança com ar de mistério diz: preciso falar em particular com alguma de vocês. Diz para a Fraidei que a Xeléia tem um tomor [tumor] e que vai precisar operar, mas que ela não deve saber. A Fofolete diz que também está sentindo dor no corpo inteiro. A dotôra manda a Fofolete se sentar na cadeira e depois de examinar escreve num pequeno pedaço de papel o nome do remédio a ser tomado: Propovit [Protovit] 29 gotas às 3, 2, 6, 8 e à meia noite e, em seguida, grita: próximo! Uma auxiliar de enfermagem assiste às consultas, sorridente $(\mathrm{O} .4, \mathrm{D})$.
A arte do teatro Clown no cuidado

às crianças hospitalizadas

Lima RAG, Azevedo EF, Nascimento LC, Rocha SMM 
A literatura(1,6-7) tem apresentado evidências da superioridade da dramatização se comparada à comunicação verbal, principalmente, quando se trata de pré-escolares e escolares. Assim, a proposta da Cia do Riso, como já mencionado, é utilizar técnicas do teatro clown com a finalidade de promover e estimular o riso e a imaginação das crianças durante o processo de hospitalização. Chama atenção, ainda, para o fato de que as funções do hospital, na atualidade, devem ser revistas, pois já não é mais um local somente de dor e sofrimento.

Observamos que o elogio é uma estratégia que melhora a auto-estima e a auto-confiança da criança, por isso deve ser utilizado, também, no hospital. Para exemplificar:

\begin{abstract}
A Flaflu e a Xeléia se aproximam da criança e dizem que o cabelo dela é lindo. Que mesmo no hospital ela pode continuar cuidando do cabelo. A criança sorri com os elogios palhaçais $(0.9, \mathrm{I})$.
\end{abstract}

Pipoca diz: você tem um sorriso tão meigo [...] devia sorrir mais! Pode chorar quando tiver com dor ou com medo, mas lembre-se de sorrir mais vezes [...] A criança sorri novamente $(0.1, N 3)$

Esta observação leva-nos a refletir sobre os benefícios da alegria, do humor e do riso em nossas vidas, manifestações estas que nos colocam na condição de seres humanos ${ }^{(7)}$. No contexto hospitalar, o sorriso resultante da interação entre criança e a arte do teatro clown revela que, de alguma forma, ela dominou seu sofrimento e as dificuldades para compartilhar uma atitude de vida, possibilidade que se estende também aos seus familiares e à equipe de saúde.

\section{DISCUSSÃO}

Os temas apresentados nos resultados são decorrentes do terceiro passo da técnica de coleta de dados, observação seletiva. Essa técnica procurou atender ao objetivo do trabalho, que era evidenciar aspectos da interação entre personagens do teatro clown e crianças hospitalizadas.

É inquestionável os avanços da prática médica, principalmente nas últimas três décadas, mas mesmo assim esta medicina não consegue dar respostas a inúmeras questões que envolvem o adoecimento e a hospitalização ${ }^{(4)}$. Ao tentar transformar o hospital num espaço terapêutico, a medicina do século $X X$ tornou-o biologicista, com produção de cuidados sustentada por uma tecnologia especializada e de alto custo. No hospital, as regras pautadas na disciplina, eficiência e hierarquização de saberes produzem rotinas que, geralmente, deixam pouco aos usuários para expressarem sua singularidade e autonomia(15). No caso das crianças e adolescentes as atividades diárias são programadas em torno das doenças, por exemplo, as rotinas mais simples como as de higiene, alimentação, sono e repouso; ir à escola e brincar sofrem modificação, do mesmo modo que os horários. Com relação ao sono e à alimentação, o primeiro pode ser interrompido a depender dos procedi- mentos, e a alimentação restrita ou até suspensa. Nestas condições, o hospital pode ser percebido pela criança como local associado à dor, sofrimento, castigo e isolamento ${ }^{(1-2)}$.

A produção de cuidados voltada para a humanização pressupõe como requisitos atendimento de qualidade, participação social do usuário, melhora na relação entre profissionais e usuários e respeito à singularidade e aos direitos de cada usuário. Um hospital que se utiliza da filosofia da humanização contempla, em sua estrutura física, tecnológica, administrativa e humana, o respeito e a valorização da pessoa humana, seja ela paciente, familiar ou o próprio profissional de saúde. A observância desses pressupostos pode garantir condições para o atendimento de qualidade e o respeito à dignidade ${ }^{(16)}$.

No caso do cuidado pediátrico, ao se proporem estratégias que contemplem as necessidades da criança, merece destaque a atividade básica da infância - o brincar. Em nosso país, o artigo 9으 da Declaração dos Direitos da Criança e Adolescente Hospitalizados, trata do direito ao desfrute de alguma forma de recreação(17). No entanto, a realidade de grande parte das instituições hospitalares brasileiras não tem permitido que elas coloquem em prática as determinações da referida declaração.

A importância do clown na assistência à criança hospitalizada mereceu destaque em artigo publicado na revista Lancet, que descreve algumas interações entre os clowns e as crianças e, ainda aponta, como estas auxiliam no enfrentamento da doença e no processo de hospitalização, pois ajudam a criança a se encontrar e ser proprietária do ambiente hospitalar, bem como enfrentar sons e silêncios; preservar sua intimidade; conviver com as teorias médicas e suas próprias fantasias; facilitar a convivência da criança com seu corpo e emoções; transformar o ambiente hospitalar e colaborar com a equipe de saúde ${ }^{(9)}$.

O clown, elemento humanizante das relações, tem suas origens fincadas na ingenuidade e pureza. Ele coloca à disposição do paciente o prazer de rir, amplia sua perspectiva de vida e the mostra outras possibilidades no processo da cura. No momento em que ri, a criança e o adolescente demonstram que a sua posição de paciente se transfere para a de agente de sua própria alegria, podendo seu corpo de dor ser transformado em um corpo de riso ${ }^{(7)}$.

Na atualidade, as enfermeiras pediatras têm se questionado se apenas os aspectos clínicos são suficientes para o desempenho de suas práticas, considerando que os elementos humanísticos e artísticos poderiam ser parte integrante do ensino e, conseqüentemente, da prática de enfermagem. Nesta perspectiva, o cuidado de enfermagem não pode ser desenvolvido unicamente a partir do conhecimento das ciências físicas e sociais, negligenciando as artes e humanites $^{(18)}$. Nesse sentido, as artes e a filosofia são fundamentais para o desenvolvimento de um cuidado integral e personalizado, como o proposto pela Cia do Riso, pois elas permitem se chegar a um conhecimento mais abrangente e preciso da realidade humana, do mundo individual e coletivo. 
No caso específico da música, sua utilização como recurso terapêutico esteve presente ao longo da história da medicina em cada civilização e época. Para exemplificar, na Bíblia há relatos de que por volta de 1000 a.C., Davi tocava harpa para aliviar e acalmar o rei Saul dos maus espíritos. $\mathrm{Na}$ atualidade, os estudos ${ }^{(13,19)}$ apresentam evidências de que a música pode ser empregada como mais um instrumento no tratamento de inúmeras doenças, principalmente quando é necessário se estabelecerem estratégias para o alívio da dor.

A criança ao ser hospitalizada pode manifestar protesto, medo, apatia, fuga, sentimento de culpa e de tristeza ${ }^{(1,4)}$, e ao experimentar rotinas diferentes e dolorosas decorrentes dos procedimentos invasivos, preocupa-se, com sua integridade física, especialmente com a possibilidade de mutilação. Trabalhos recentes ${ }^{(13,19)}$ apontam que a música pode reduzir a tensão, ansiedade e situações estressantes, como as da hospitalização; assim como diminuir a dor e promover melhora na qualidade do sono, por isso se constitui num valioso método de distração. Estudo randomizado ${ }^{(19)}$ realizado com 40 crianças na faixa etária de 5 a 12 anos de idade, hospitalizadas para pequenas cirurgias em um hospital italiano, demonstrou que a presença do clown e dos pais, durante a indução anestésica, foi uma intervenção efetiva para reduzir a ansiedade tanto das crianças quanto de seus pais.

A leitura terapêutica, um outro recurso utilizado como forma de comunicação com a criança hospitalizada, torna possível uma relação mais intuitiva com as crianças, por facilitar a compreensão do não-verbal. Sendo assim, elas devem se valer da literatura, pois, através das fábulas e dos contos fantásticos, acessíveis à sua compreensão, desafogam emoções fortes, como raiva, medo, dor e sofrimento.

\section{LIMITAÇÕES DO ESTUDO}

A observação participante não apreende o universo do ambiente físico e social; restringe-se a estudo de casos par-

\section{REFERÊNCIAS}

1. Whaley LF, Wong DL. Enfermagem pediátrica: elementos essenciais à intervenção efetiva. 5a ed. Rio de Janeiro: Guanabara Koogan; 1999.

2. Oliveira H. Ouvindo a criança sobre a enfermidade e a hospitalização. In: Ceccim RB, Carvalho PRA, organizadores. Criança hospitalizada: atenção integral como escuta à vida. Porto Alegre: Editora da Universidade Federal do Rio Grande do Sul; 1997. p. 42-55.

3. Vieira MA, Lima RAG. Convivendo com mudanças: vivências de crianças e adolescentes com doença crônica. Rev Lat Am Enferm. 2002;10(3):23-30. ticulares e não à amostra populacionais. Seus resultados, portanto, devem ser confrontados com a literatura para a apreensão do que é comparável com o conhecimento produzido nesta área e o conhecimento gerado aplicável ao caso específico.

\section{CONSIDERAÇÕES FINAIS}

Os avanços no cuidado à saúde da criança não eliminam a necessidade de hospitalização em alguns casos e, quando isto ocorre, ela pode ser exposta a riscos. Se uma criança se sente descontraída e feliz, sua permanência no hospital torna-se mais fácil, e do mesmo modo seu processo de desenvolvimento pode ser favorecido.

A interação com a criança hospitalizada, através da arte do teatro clown, pode ser ampliada com a participação dos pais ou cuidadores e da própria equipe de saúde. Colocar em cena o lado saudável não só da criança, mas também dos seus pais ou cuidadores contribui para redimensionar o processo de trabalho com a composição do técnico e do lúdico.

O hospital não é um ambiente apenas de dor e sofrimento, nele sempre há um espaço que deve ser aproveitado para o desenvolvimento de atividades lúdicas, pedagógicas e recreacionais, pois a internação não deve interromper o desenvolvimento infantil. Mesmo que não haja a presença do clown durante todo o tempo, os profissionais podem tornar-se terapêuticos ao utilizarem outras formas de expressão artística, como mediação de histórias infanto-juvenis, música, dramatização, ecologia hospitalar apropriada e brinquedos, entre outros. Nesse sentido, expressões artísticas como forma de comunicação, participação do binômio criança e acompanhante e o clown como recurso terapêutico revelam as possibilidades de utilização do teatro clown como uma modalidade terapêutica no complexo cuidado hospitalar.

4. Mitre RMA, Gomes R. A promoção do brincar no contexto da hospitalização infantil enquanto ação de saúde. Ciênc Saúde Coletiva. 2004;9(1):147-54.

5. Mello CO, Goulart CMT, Ew RA, Moreira AM, Sperb TM. Brincar no hospital: assunto para discutir e praticar. Psicol Teoria Pesq. 1999;15(1):65-74.

6. Françani GM, Zilioli D, Silva PRF, Santana RPM, Lima RAG. Prescrição do dia: infusão de alegria. Utilizando a arte como um instrumento na assistência à criança hospitalizada. Rev Lat Am Enferm. 1998;6(5):27-33.

7. Massetti M. Soluções de palhaços: transformações na realidade hospitalar. 7a ed. São Paulo: Palas Atlas; 2007. 
8. Massetti M. Boas misturas: a ética da alegria no contexto hospitalar. São Paulo: Palas Athena; 2003.

9. Oppenheim D, Simonds C, Hartmann O. Clowning on children's wards. Lancet. 1997;350(9094):1838-40.

10. Bogdan R, Biklen S. Investigação qualitativa em saúde: uma introdução à teoria e aos métodos. Porto: Porto; 1994.

11. Deslandes SF, Assis SG. Abordagens quantitativa e qualitativa em saúde: o diálogo das diferenças. In: Minayo MCS, Deslandes SF, organizadores. Caminhos do pensamento: epistemologia e método. Rio de Janeiro: FIOCRUZ; 2002. p. 195-219.

12. Flick U. Uma introdução à pesquisa qualitativa. 2a ed. Porto Alegre: Bookman; 2004.

13. Ferreira CCM, Remedi PP, Lima RAG. A música como recurso no cuido à criança hospitalizada: uma intervenção possível? Rev Bras Enferm. 2006;59(5):689-93.

14. Pedro ICS, Nascimento LC, Poleti LC, Lima RAGL, Mello DF, Luiz FMR. O brincar em sala de espera de um ambulatório infantil na perspectiva de crianças e seus acompanhantes. Rev Lat Am Enferm. 2007;15(2):290-7.
15. Mitre RMA. O brincar no processo de humanização da produção de cuidados pediátricos. In: Deslandes SF, organizadora. Humanização dos cuidados em saúde: conceitos, dilemas e práticas. Rio de Janeiro: FIOCRUZ; 2006. p. 283-300.

16. Backes DS, Lunardi Filho W, Lunardi VL. O processo de humanização do ambiente hospitalar centrado no trabalhador. Rev Esc Enferm USP. 2006;40(2):221-7.

17. Brasil. Conselho Nacional dos Direitos da Criança e do Adolescente. Resolução n. 41, de 13 de outubro de 1995. Dispõe sobre os Direitos da Criança e do Adolescente Hospitalizados. Diário Oficial da União, Brasília, 17 out. 1995. Seção 1, p. $16319-20$.

18. Darbyshire P. Understanding caring through arts and humanities: a medical/nursing humanities approach to promoting alternative experiences of thinking and learning. J Adv Nurs. 1994;19(5):856-63.

19. Vagnoli L, Caprilli S, Robiglio A, Messeri A. Clown doctors as a treatment for preoperative in children: a randomized, prospective study. Pediatrics. 2005;116(4):e563-7.

\section{Financiamento do Projeto}

Conselho Nacional de Desenvolvimento Científico e Tecnológico - CNPq - Processo no 521081/98-0; Fundação de Amparo à Pesquisa do Estado de São Paulo - FAPESP no 2001/10764-0. 